Supporting Information

\title{
Calculations of $\mathrm{pH}-$ Dependent Binding of Proteins to Biological
}

\section{Membranes}

Maja Mihajlovic, Themis Lazaridis*

Validation of the $\mathrm{pK}_{\mathrm{a}}$ Calculations

The combinatorial method used for $\mathrm{pK}_{\mathrm{a}}$ calculations was tested on selected acidic residues of turkey ovomucoid third domain (OMT). $1.3 \mathrm{~ns}$ molecular dynamics simulations in solution were performed starting from the crystal structure (the PDB entry 1PPF) at $\mathrm{T}=298 \mathrm{~K}$, using the Nosé-Hoover thermostat. The computed and the experimental $\mathrm{pK}_{\mathrm{a}}$ values, ${ }^{1}$ are given in Table $\mathrm{S} 1$. The experimental $\mathrm{pK}_{\mathrm{a}}{ }^{\text {'s }}$ are measured at $10 \mathrm{mM}$ salt concentration; although EEF1 does not take salt concentration as an input parameter, the solvation parameters and thus the calculated $\mathrm{pKa}$ values correspond to low ionic strength conditions. ${ }^{2}$ The $\mathrm{pK}_{\mathrm{a}}$ values of ASP7, GLU10 and ASP27 are very close to the experimental values. The $\mathrm{pK}_{\mathrm{a}}$ value of GLU43, located at the protein surface and exposed to solvent, is $1 \mathrm{pH}$ unit underestimated as compared to the experimental value. No other interactions except for sporadic hydrogen bonds between the carboxyl oxygens of GLU43 and the HD21 and HD22 of ASN39 have been identified. 
The $\mathrm{pK}_{\mathrm{a}}$ value of GLU19, on the other hand, disagrees with the experimental value. As suggested by Schaller and Robertson, ${ }^{1}$ the low $\mathrm{pK}_{\mathrm{a}}$ value of GLU19 is due to hydrogen bonding between its carboxyl oxygens and the hydroxyl group of THR17 and the NH of GLU19. In the 1PPF structure, the distance between the OE1 of GLU19 and the HG1 of THR17 is 3.1 $\AA$, whereas the distance between the OE1 of GLU19 and the H of GLU19 is $\sim 1.9 \AA$. Our calculations performed on the unrefined $1 \mathrm{PPF}$ yield a $\mathrm{pK}_{\mathrm{a}}$ of 4.0 of GLU19. However, the hydrogen bonds observed in the 1PPF structure break during MD simulations and are replaced by salt bridges with ARG21 and with LYS34. Although these should also be stabilizing, the interaction energy between the deprotonated GLU19 and ARG21 is by $\sim 2.0 \mathrm{kcal} / \mathrm{mol}$ less negative compared to that of the protonated GLU19. The largest contribution comes from electrostatic energy $(\sim 2.4 \mathrm{kcal} / \mathrm{mol})$. This could be another example of problems modeling ARG in EEF1. ${ }^{2,3}$ In conclusion, the discrepancy in the $\mathrm{pK}_{\mathrm{a}}$ value of GLU19 is most likely due to force field inadequacies.

Table $\mathrm{S} 1$ shows the $\mathrm{pKa}$ values of acidic residues in OMT calculated using other methods $^{4-9}$ and respective RMS deviations. Compared to others, the RMSD of our calculations is rather large. However, much of it is due to the GLU19 problems described above. If that value is omitted in the RMSD calculation, the performance of our calculations is comparable with that of other methods ( $\mathrm{RMSD}=0.5)$.

\section{References}

(1) Schaller, W.; Robertson, A. D. Biochemistry 1995, 34, 4714.

(2) Masunov, A.; Lazaridis, T. J. Am. Chem. Soc. 2003, 125, 1722.

(3) Mottamal, M.; Zhang, J.; Lazaridis, T. Proteins in press. 
(4) Forsyth, W. R.; Gilson, M. K.; Antosiewicz, J.; Jaren, O. R.; Robertson, A. D. Biochemistry 1998, 37, 8643.

11145.

(5) Havranek, J. J.; Harbury, P. B. Proc. Natl. Acad. Sci. USA 1999, 96,

(6) Mehler, E. L.; Guarnieri, F. Biophys. J. 1999, 75, 3.

(7) Li, H.; Robertson, A. D.; Jensen, J. H. Proteins 2004, 55, 689.

(8) Khandogin, J.; Brooks, C. L. III Biophys. J. 2005, 89, 141.

(9) Mao, J.; Gunner, M. R. manuscript in preparation.

Table S1. The calculated $\mathrm{pK}_{\mathrm{a}}$ values of the selected acidic residues in turkey ovomucoid. The experimental $\mathrm{pK}_{\mathrm{a}}$ values are obtained from Schaller and Robertson. ${ }^{1}$

\begin{tabular}{|c|c|c|c|c|c|c|c|c|}
\hline residue & Exp. & Calc. & $P B^{*}$ & MTK $^{\#}$ & $S C P^{8}$ & $Q M / P B^{\dagger}$ & CPHMD & $M C C E^{S S}$ \\
\hline D7 & 2.7 & 2.6 & 2.9 & 2.1 & 2.9 & 2.4 & 2.8 & 3.1 \\
\hline E10 & 4.1 & 4.5 & 3.4 & 4.0 & 4.1 & 4.3 & 3.1 & 3.9 \\
\hline E19 & 3.2 & 5.4 & 3.2 & 3.1 & 3.6 & 2.7 & 2.3 & 3.3 \\
\hline D27 & 2.3 & 2.5 & 4.0 & 2.9 & 3.3 & 1.9 & 4.7 & 3.2 \\
\hline E43 & 4.8 & 3.8 & 4.3 & 5.6 & 4.4 & 4.5 & 5.3 & 4.5 \\
\hline $\mathrm{rmsd}^{\mathfrak{E}}$ & - & 1.1 & 0.9 & 0.5 & 0.5 & 0.3 & 1.2 & 0.5 \\
\hline
\end{tabular}

${ }^{\bar{E}} \mathrm{RMS}$ deviation calculated as: $\mathrm{RMSD}=\left[(1 / \mathrm{N}) \sum_{\mathrm{i}=1}{ }^{\mathrm{N}}\left(\mathrm{pK}_{\mathrm{a}, \text { exp }, \mathrm{i}}-\mathrm{pK}_{\mathrm{a}, \mathrm{cal}, \mathrm{i}}\right)^{2}\right]^{0.5}$, where $\mathrm{N}$ is the number of $\mathrm{pK}_{\mathrm{a}}$ values, $\mathrm{pK}_{\mathrm{a}, \text { exp }}$ is the measured $\mathrm{pK}_{\mathrm{a}}$ and $\mathrm{pK}_{\mathrm{a}, \text { calc }}$ is the calculated $\mathrm{pK}_{\mathrm{a}}$.

* The Poisson-Boltzmann equation based calculations performed on crystal structure (1PPF), with the dielectric constant of the protein $\square_{p}=20{ }^{4}$

\# The modified Tanford-Kirkwood continuum electrostatic calculations on crystal structure with $\square_{0}=4 .^{5}$

${ }^{\S}$ A self-consistent approach based on sigmoidally screened Coulomb potentials. ${ }^{6}$

${ }^{\dagger} \mathrm{Ab}$ initio quantum mechanical calculations on parts of $1 \mathrm{PPF}$, consisting of the ionizable residue and interacting residues, combined with the linear Poisson-Boltzmann equation for bulk solvent. ${ }^{7}$

$\$$ Constant $\mathrm{pH}$ molecular dynamics with proton tautomerism. ${ }^{8}$

$\S \S$ Multi-conformation continuum electrostatics. ${ }^{9}$ 